SIR-The undersigned are members of a subcommittee empowered by the International Committee on the Taxonomy of Viruses to propose an appropriate name for the retrovirus isolates recently implicated as the causative agents of the acquired immune deficiency syndrome (AIDS). Adoption of an internationally acceptable name for this group of viruses has become an important issue because of the widespread interest in AIDS and its origins and because of the multiplicity of names currently in use. Thus the several isolates of what are now evidently closely related members of the same virus group have been called lymphadenopathy-associated virus (LAV), human T-lymphotropic lymphotropic virus type III (HTLV-III), immunodeficiency-associated virus (IDAV), and AIDS-associated retrovirus (ARV). At present, two compound names (HTLV-III/LAV and LAV/ HTLV-III) are also used in publications, while the colloquial name, the AIDS virus, is often used by the general press.

We propose that the AIDS retroviruses be officially designated as the human immunodeficiency viruses, to be known in abbreviated form as HIV.

We have considered several issues bearing on this proposal.

(1) The name should conform to common nomenclature for retroviruses, beginning with the host species ("human"), ending with "virus", and containing a word that denotes a major (though not the only) pathogenetic property of the prototypic members of the group ("immunodeficiency"). ("Feline leukaemia virus" and "mouse mammary tumour virus" are two well-known examples of such names for retrovirus species.)

(2) Though the name should clearly link the viruses to the disease with which they are associated, it should not incorporate the term "AIDS", which many clinicians urged us to avoid.

(3) The name should be readily distinguished from all existing names for this group of viruses and has been chosen without regard to priority of discovery.

(4) The name should be sufficiently distinct from the names of other retroviruses to imply an independent virus species, a group of isolates that can presumably exchange genetic information readily with each other but not with members of other known retrovirus species. These other species include the human T-cell leukaemia viruses (for example, HTLV-1 and HTLV-2), which will continue to be named according to a convention adopted by several leading investigators in September 1983. (Though roman numerals are often used to indicate the type of HTLV, arabic numbers were originally prescribed in the agreement and are thus used here.)

(5) Retroviruses isolated from subhuman primates and found to be genetically related and biologically similar to HIVs should be designated as immunodeficiency viruses of the appropriate host species (for example, simian immunodeficiency virus [SIV] or African green monkey immunodeficiency virus [AGMIV]).

(6) Because HIV isolates are numerous and display considerable genetic heterogeneity, particularly in the env gene, it will be necessary for each laboratory to assign subspecies designations to their isolates. We recommend that each laboratory adopt a code with geographically informative letters and sequential numbers to identify their isolates (for example, the 42 nd isolate at the University of Chicago could be described as HIV [CHI-42]). Initially, the existing, well-characterized isolates, such as LAV-1, HTLV-IIIB or ARV-2, should be identified as such in publications to ease the transition to a unified nomenclature.

(7) Any future isolates of human retroviruses with clear but limited relationship to isolates of HIV (for example, more than 20 per cent but less than 50 per cent nucleic acid sequence identity) should not be called HIV unless there are compelling biological and structural similarities to existing members of the group.

We hope that this proposal will be adopted rapidly by the research community

\section{Disposal of British civil plutonium}

SIR-The stated position of the Central Electricity Generating Board (CEGB) on British civil plutonium (Nature 318, 406; 1985) has for its keystone an apparent material inaccuracy of very considerable magnitude, namely, the claim that "no plutonium produced in CEGB reactors has been... exported for use in weapons". Three apparent facts indicate that the claim is false.

First, CEGB is party to a statement that "... approximately four tonnes..." of such plutonium has been exported to the United States under the provisions of the 1958 Mutual Defence Agreement and its 1959 Amendment, Cmnd 859 (The Electrical Power Engineer, p.163, August/ September 1984).

Second, Paragraph C of Article V of Cmnd 859 specifies an exclusive use of this plutonium: "the preparation or implementation of defence plans". (Colloquially, this appears to mean bomb tests and bombs.)

Third, and setting the issue beyond reasonable doubt, a spokesman for the US government has recently stated that "...the Mutual Defence Agreement actu- working with viruses.

JoHn Coffin (Tufts University, Medford, Massachusetts, USA), Ashley HAASE (University of Minnesota, Minneapolis, Minnesota, USA), JAY A. LEVY (University of California, San Francisco, California, USA), Luc Montagnier (Institut Pasteur, Paris, France), Steven OroszLAN (Frederick Cancer Research Center, Frederick, Maryland, USA), Natalie TeICH (Imperial Cancer Research Fund, London WC2, UK), Howard TEMIN (University of Wisconsin, Madison, Wisconsin, USA), Kumao TOYOSHIMA (University of Tokyo, Tokyo, Japan), HaROLD VARMUS, chairman (University of California, San Francisco, California, USA), Peter Vogt (University of Southern California, Los Angeles, California, USA), RoBIN WeIss (Institute of Cancer Research, Chester Beatty Laboratories, London SW3, UK)

- An earlier version of this letter asked that journals publishing it should make use of the name HIV a condition for the publication of research articles. There is much to be said for the general use of a common name, while the present proposal seems to have much to commend it (except for the possibility of misreading the last two initials as a roman "four"). Nevertheless, Nature will continue its present practice of allowing its contributors to use whatever nomenclature seems to them appropriate, while reserving the right to add a clarifying note if this should seem necessary to avoid confusion. Editor, Nature.

ally requires the United States to use all plutonium obtained from the United Kingdom under the Agreement for military purposes..." (The Electrical Power Engineer, February 1985, p38; my italics).

The apparent material inaccuracy is very considerable. Approximately 4,000 $\mathrm{kg}$ of plutonium is enough for a thousand bombs, perhaps two thousand if the design is sophisticated, more than enough to devastate the whole of Europe, or the whole of the Soviet Union, or both. Thus, the apparent involvement of the UK "civil" nuclear power programme in weapons production is on a very large scale indeed.

A similar, apparently false statement occurs in a written Parliamentary Answer published in the first weeks of the Sizewell Inquiry: "...no plutonium from the CEGB nuclear programme has ever been exported for use in weapons..." (Hansard, Commons, 4 February 1983, col. 206).

Faculty of Science,

R.V. HESKETH

Bayero University,

Kano,

Nigeria 